"The submitted manuscript has been authored by a contractor of the U.S. Government under contract No. DE-AC05-

840R21400. Accordingly, the U.S.

Government retains a nonexclusive,

royalty-free license to publish or reproduce

the published form of this contribution, or

allow others to do so, for U.S. Covernment

purposes."

CONF-901116--16

DE91 001524

\title{
ELECTRON CYCLOTRON RESONANCE MICROWAVE ION SOURCES FOR THIN
}

\section{FILM PROCESSING*}

\section{A. BERRY and S. M. GORBATKIN}

Oak Ridge National Laboratory, Oak Ridge, Tennessee 37831 USA

\begin{abstract}
Plasmas created by microwave absorption at the electron cyclotron resonance $(E C R)$ are increasingly used for a variety of plasma processes, including both etching and deposition. ECR sources efficiently couple energy to electrons and use magnetic confinement to maximize the probabihty of an electron creating an ion or free radical in pressure regimes where the mean free path for ionization is comparable to the ECR source dimensions.
\end{abstract}

The general operating principles of ECR sources are discussed with special emphasis on their use for thin film etching. Data on source performance during $\mathrm{Cl}$ based etching of Si using an ECR system are prese thed.

\section{Introduction}

Plasmas created by microwave absorption at the electron cyclotron resonance (ECR) are well suited to a variety of thin film processing applications. 1,2 ECR plasma sources were developed in the 1960) for fusion ${ }^{3}$ and thruster ${ }^{4}$ applications and were

* Research sponsored by the Division of Materials Sciences, L.S. Department of Energy uncier contract DE-ACO5-84OR21400 with Martin Marietta Energy Systems, Inc. and SEMATECH.

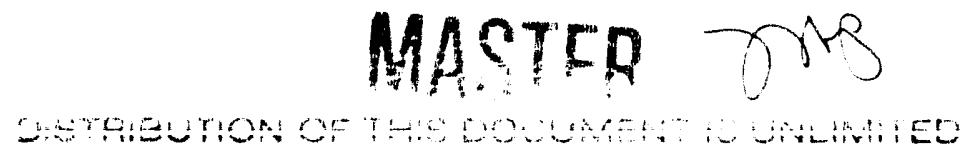


adapted in the 1970 s for use in thin film processing 5 and ion implantation. ${ }^{6}$ Since then, they have been used for deposition of $\mathrm{SiO}_{2},{ }^{7} \mathrm{Si}_{3} \mathrm{~N}_{4},{ }^{7} \mathrm{Si}, 8,9 \mathrm{SiC},{ }^{10} \mathrm{GaAs},{ }^{11} \mathrm{TaO}, 12,13$ $\mathrm{NbO},{ }^{12} \mathrm{Al}_{2} \mathrm{O}_{3},{ }^{13}$ diamond, ${ }^{14}$ and $\mathrm{BN} .{ }^{15}$ Etching has been demonstrated for $\mathrm{Si}, 8,16-19$ Mo, 18 GaAs, ${ }^{20}$ and other III-V based systems. 21 Doping 22 and taper-etching 23 applications have also been effective. ECR microwave plasma source advantages include operation over a wide pressure range; low intrinsic ion energies (as low as 10-20 eV); high gas efficiency; and electrodeless operation.

\section{Source Operating Principles}

\section{A. Two Coil Mirror}

The key to providing these advantages is a configuration which allows both direct energy absorption by electrons withoui the need for collisions (as is needed for unmagnetized microwave or radio frequency $13.56 \mathrm{MHz}$ scurces $^{2}$ ) and provides plasma confinement. An example of such a configuration is the two coil mirror, ${ }^{24}$ in which current flows through the coils to produce a magnetic field as shown in Fig. 1. Radial confinement occurs due to the tendency for electrons and ions to spiral along field lines when Larmor radii are much less than the characteristic ECR. source dimension, although some cross field transport occurs.

Energetic e'cctrons, especially those with high velocities perpendicular to the magnetic field, can be trapped in the magnetic minima due to conservation of energy and magnetic moment. This additional confinement increases the probability of ionization over that provided by radial confinement alone. Only electrons with relatively high axial velocities, usually obtained from collisional scattering, can escape the mirror and electrostatically pull ions out with them.

A resonant cyclotron interaction provides the mechanism for absorption of microwaves by electrons. When microwaves are injected as shown in Fig. 1, they tend to propagate through the plasma until the iocal electron cyclotron frequency is equal to the 
microwave frequency. This ocurrs at a field of $87.5 \mathrm{mT}$ for the $2.45 \mathrm{GHz}$ power commonly used in ECR plasma sources. At that field, the microwaves are strongly absorbed by the electrons. In practice resonance broadening due to, for example, the doppler shift in microwave frequency seen by electrons with finite axial velocities, causes absorption to occur over a range of magnetic fields, with the range increasing with electron temperature and plasma density. Absorption takes place at fields as much as 5-7 mT away from resonance for plasma parameters characteristic of ECR sources. Collisional absortion, especially at higher pressures (tens of mTorr), and parametric absortion may also be important in some circumstances. ${ }^{2}$

An important feature of the configuration, shown in Fig. 1, is high field injection, i.e., the presence of a magnetic field at the microwave entrance window which is (1) higher than field required for ECR and (2) parallel to the direction of microwave injection. When these two conditions are met, efficient plasma production can occur even in overdense plasmas where the plasma frequency is much higher than the wave frequency. Without high field injection, the $2.45 \mathrm{GHz}$ microwaves are cut off and cannot propagate through plasma densities higher than $7 \times 10^{16} \mathrm{~m}^{-3}$ (i.e., the density which correponds to a plasma frequency of $2.45 \mathrm{GHz}$ ). High field injection is also applicable in single coil (no mirror) ECR configurations.

\section{B. Multipole ronfigurations}

Additional radial confinement and improved plasma uniformity can be obtained by using a multipole bucket below or as an integral part of the primary plasma source as shown in Fig 2.25 Each cusp of the multipole magnetic field acts like the field maximum in the magnetic mirror and effectively confines a majority of the plasma. If high field permanent magnets, such as samarium cobalt, are used to form the multipole fields, microwave antennas can be placed at the cusps to use the resonant magnetic field there to both create and confine the plasma. 26 
Other ECR source configurations which provide both enhanced plasma production and confinement include those based on tunable microwave cavities. These sources, which often also use a bucket to provide radial confinement and uniformity, have been developed extensively and have been reviewed elsewhere. 27

\section{General Operating Characteristics}

Typical operating characteristics of systems currently used for deposition and etching include a microwave frequency of $2.45 \mathrm{GHz}$, pressures of $0.1-5 \mathrm{mTorr}$, microwave powers of $100-2000 \mathrm{~W}$, chamber diameters of $0.08-0.1 \mathrm{~m}$ (the characteristic of an S-band waveguide) to 0.3-0.4 m. Under these conditions, plasma densities of $10^{17}$ to $10^{18} \mathrm{~m}^{-3} 28$ with ion energies below $40 \mathrm{ev}^{29,30}$ are obtained. Higher pressures tend to be used for deposition.

Uniformity over large ( $>6$ " diam) areas is often achieved, regardless of the specific ECR source design, by utilizing a multipole bucket configuration. 31 A measure of the overall source performance is the power required to produce an ampere of useful ion current. This power is in the 200-300 watts per ampere range and is remarkably constant for optimized ECR sources of all types.

\section{Etching}

\section{A. General Etching Requirements}

The importance of ion energy control is perhaps most clearly illustrated in the etching of silicon in a chorine plasma for semiconductor device processing. In a typical cmos device a $\sim 0.5 \mu \mathrm{m}$ layer of polysilicon (which will ultimately form the gate electrode) is deposited on top of a much thinner layer of $\mathrm{SiO}_{2}$ (the gate oxide). The gate is then formed by etching. An attractive etch provess must simultaneously maximize the removal rate of silicon while minimizing both the ecching of and damage to the underlying oxide. In addition the resist removal rate must be low enough to maintain the feature definition 
needed for submicron scale devices. For economic reasons, Si etch rates of $0.3-0.6 \mu \mathrm{m}$ per minute are needed. At the same time rates $\sim 100$ times lower for oxide and $\sim 5$ times lower for resist are desired. The best ion energy range for high $\mathrm{Si} / \mathrm{SiO}_{2}$ selectivity is probably in the range of $20-40 \mathrm{eV} .29$ Oxide selcctivies of 280 have been observed in an optimized ECR reactor. ${ }^{19}$ The low ion energies well also help avoid lattice damage to the gate oxide.

Directional etching is needed for producing the needed device geometries when the characteristic feature size $i$, the same as the layer thickness. Otherwise the features defined by the mask are distorted. The low pressures of ECR source operation help achieve directional etching by minimizing scattering of gas species to feature side walls and by allowing ion energy control. Chlorine based processes are good candidates for directional etching because at room temperature and low pressure chlorine free radicals do not spontaneously etch silicon 32 and the intrinsically anisotropic character of an ion dominated etch process can be utilized.

For equipment design, feed material throughput is an important consideration at low pressures. As both the wafer diameter and desired etch rate increase, the pumping speed may become a limiting factor. For example, an etch rate of $5000 \mathrm{~A} / \mathrm{min}$ over an 8 " diam Si wafer would, at $1 \mathrm{~m}$ Torr, require a pumping speed of $\sim 400 \mathrm{l} / \mathrm{sec}$ for the etched Si material alone. Additional pumping would be riquired for unused process gas.

\section{B. Example: Etch selectivity of $\mathrm{Si}_{/} / \mathrm{SiO}_{2}$}

Etch selectivities have been measured in a $\mathrm{Cl}_{2}$ based $\mathrm{Si}$ etch system. The system is a combination of an Astex mirror field source 28 and auxiliary magnets to improve radial uniformity. These magnets are unlikely to affect the qualitive trends discussed below. For these experiments the upper and lower source magnets were positioned $-(0.015 \mathrm{~m}$ above and $0.20 \mathrm{~m}$ below thie vacuum surface of the microwave window with currents of $200 \mathrm{~A}$ and 170 A respectively. These positions and currents were used for the calculations shown 
in Fig. 1. The chlorine flow rate was $20 \mathrm{sccm}$ at a pressure of $0.37 \mathrm{mTorr}$ before striking a plasma. The pressure was chosen to allow illustration of the importance of ion energy control for semiconductor etch applications using in situ reflectometry as the sole film thickness measurement technique. The selectivities of $\mathrm{Si} / \mathrm{SiO}_{2}$ obtained (up to $\sim 10$ ) are inadequate for many manufacturing processes, but higher selectivities are obtainable by using different operating conditions 17 as well as different source configrations. ${ }^{19}$. The pressure with a plasma was approximately $0.2 \mathrm{mTorr}$ when silicon was being etched and $0.24 \mathrm{mTorr}$ when oxide was under process. All pressures were measured in the process chamber downstream of the mirror source and behind the auxiliary magnets.

The key feature of the source is the ability to control the ion energy down to a few tens of $\mathrm{eV}$ and access the window of ion energy which yields improved selectivity of $\mathrm{Si} / \mathrm{SiO}_{2}$. The lowest possible energy is determined by plasma space potentials. Source Langmuir probe characteristics have been taken and analyzed using the same approach as described in ref 28. Under conditions similar to those etch experiment described above, the difference between the space and floating potentials is typically $20-25$ volts. Plasma densities measured $\sim 2 \mathrm{~cm}$ above the wafer were $\sim 2 \times 10^{11} \mathrm{~cm}^{-3}$, and electron temperatures were $\sim 2.5-3 \mathrm{eV}$. Additional ion energy was provided by applying $13.56 \mathrm{MHz}$ rf power to the floating wafer holder. The average dc voltage produced, $V_{\mathrm{dc}}$, was measured at the holder. The exact relationship between $V_{\mathrm{dc}}$ and the incremental energy the bias gives to ions is not well understood because the wafer itself is insulated from the chuck and the rf power is capcitively coupled to the wafer front surface. Thus, only qualitative trends for ion energies may be inferred from measurements of plasma potentials and $V_{d c}$.

Silicon etch rates were measured by taking the time between minima in the reflected light of a normal incidence $785 \mathrm{~nm}$ solid state laser. Figure 3 shows a typical reflected light signal. Plasma light contributes to this signal as can be seen by the increases in reflected light when the plasma is on. During periods a and e, the laser is on but the discharge is 
off. The minima seen in time interval b occurs during polysilicon etching when the the phase shift in reflected light from the top and bottom surface of the polysilicon is $\pi$ (one half wavelength path difference). Two consecutive minima in Fig. 3 corresponds to a thickness of $97.5 \mathrm{~nm}$ assuming an index of refraction of 2 . After the roughly $400 \mathrm{~nm}$ of silicon clears, a slower and less distinct variation in reflected light is seen in time interval c. The variation consists of a slow rise, a maximum, and a fall that takes about one third the time of the rise. The constant level of reflected light in interval $d$ indicates reflection from a single interface and signals the removal of the approximately $100 \mathrm{~nm}$ of oxide that is typical of the $6 "$ test wafers used in this experiment. The time for the oxide to clear obtained by analyzing this signal typically has an estimated uncertainty of 2-3\% because of the relatively gradual changes in slope. Oxide thicknesses of $100 \mathrm{~nm}$ were used to estimate rates based on measurements of similarly processed wafers.

Another indication of oxide etching was observed in the operating pressure, which increased about $20 \%$ when oxide was first exposed to the plasma and then fell back to the original value at about the time the oxide layer had cleared. The lower pressure present when $\mathrm{Si}$ is being etched may be due to the greater number of chlorene atoms tied up in the form of $\mathrm{Si} \mathrm{Cl}_{4}$ (as opposed to being present as the $\mathrm{Cl}_{2}$ feed gas). Since the interferometer only monitors the central portion of the wafer, monitoring the pressure was useful for checking global etch response. Fitch rates determined using a the pressure measurement agreed to those obtained from the interferometer to within $5 \%$.

Polysilicon and $\mathrm{SiO}_{2}$ etch rates were measured for applied biases $\mathrm{V}_{\mathrm{dc}}$ in the range 10-80 V. Measurements were attempted with no applied bias but the silicon etch rates were observed to decrease as a function of time. This is likely due to the competition between etching and the deposition of polymer films formed from etched photoresist remnants (which has been seen in SEM examination of wafers from similar experiments).

As shown in Fig. 4, both the silicon and oxide etch rates decrease with decreases in $\mathrm{V}_{\mathrm{dc}}$ (and thus ion energies). The selectivity of $\mathrm{Si}$ with respect to $\mathrm{SiO}_{2}$ is shown in Fig. 5 
and increases sharply at low $\mathrm{V}_{\mathrm{dc}}$. As previously mentioned, the selectivity of about 10 at the lowest energy in this configuration is less than desired for submicron feature etching and or configurations. It should be noted that hydromarbons from the resist material, which are observed to decrease apparent $\mathrm{Si}$ etch rates, may also enhance the etch rate of $\mathrm{SiO}_{2}$ due to chemical interactions. 17

\section{Summary}

ECR plasma sources are being used for an increasing variety of materials processing applications. They are well suited for those applications which require control over ion energies while still maintaining high current densities (10s of $\left.\mathrm{mA} / \mathrm{cm}^{2}\right)$ at ion energies less than $100 \mathrm{eV}$. Selectivity measurements using an ECR source show the importance of ion energy control for Si etching using $\mathrm{Cl}$-based chemistries.

\section{References}

[1]W. H. Holber, "ECR Ion Source," in Handbook of Ion Beam Processing Technology, Priñciples, Deposition, Film Modification and Synthesis, edited by J. J. Cuomo, S. M. Rossnagel, H. R. Kaufmann (Royes Publication, New Jersey), 1989.

[2]J. Musil, "Microwave Plasma: Its Characteristics and Applications in Thin Film Technology," Vacuum 36 (1986) 161.

[3]W. B. Ard, M. C. Becker, R. A. Dandl, H. O. Eason, A.C. England, R. J. Kerr, "Neutron Production from a Steady-State, Hot-Electron, Deuterium Plasma," Phys. Rev. Lett., Vol. 10, No. 3, (February 1963) 87.

[4]D. B. Miller and G. W. Bethke, "Cyclotron Resonance Thruster Design Techniques," AIAA Journal 4 (May 1966) 835.

[5]K. Suzuki, S. Okudaira, N. Sakudo and I. Kanomata, "Microwave Plasma Etching," Japanese Journal of Appl. Phys. Vol. 16 (November 1977) 1979. 
[6]N. Sakudo, K. Tokiguchi, H. Koike, and I. Kanomata, "Microwave Ion Source," Rev. Sci. Instrum., Vol. 48, No. 7, (July 1977) 762.

[7]S. Matsuo and M. Kiuchi, "Low Temperature Chemical Vapor Deposition Method Utilizing an Electron Cyclotron Resonance Plasma," Japanese Journal of Appl. Phys. Vol. 22, No. 4, (April 1983) L210.

[8]R. R. Burke, J. Pelletier, C. Pomot, and L. Vallier, "Distributed Electron Cyclotron Resonance in Silicon Processing: Epitaxy and Etching," J. Vac. Sci. Technol. A 8 (3), (May/Jun 1990) 2931.

[9]S. R. Mejia, R. D. McLeod, K. C. Kao, and H. C. Card, "Electron-CyclotronResonant Microwave Plasma System for Thin-Film Deposition," Rev. Sci. Instrum. 57 (3), (March 1986) 493.

[10]A. Chayahara, A. Masuda, T. Imura, and Y. Osaka, "Formation of Polycrystalline SiC in ECR Plasma," Japanese Journal of Appl. Phys. Vol. 25, No. 7, (July 1986) L564.

[11]Y. Tanaka, Y. Kunitsugo, I. Suemune, Y. Honda, Y. Kan, and M. Yamanishi, "LowTemperature GaAs Epitaxial Growth Using Electron-Cyclotron Resonance/MetalorganicMolecular-Beam Epitaxy," J. Appl. Phys. 64 (5), (September 1988) 2778.

[12]I. Watanabe and H. Yoshihara, "Ta-O (Ta-oxide) and $\mathrm{Nb}-\mathrm{O}$ (Nb-oxide) Film Deposition Using an Electron Cyclotron Resonance Plasma," Japanese Journal of Appl. Phys. Vol. 24, No. 6, (June 1985) L411.

[13]T. Ono, C. Takahashi, and S. Matsuo, "Electron Cyclotron Resonance Plasma Deposition Technique Using Raw Material Supply by Sputtering," Japanese Journal of Appl. Phys. Vol. 23, No. 8, (August 1984) L534.

[14]H. Kawarada, K. S. Mar, and A. Hiraki, "Large Area Chemical Vapour Deposition of Diamond Particles and Films Using Magneto-Microwave Plasma," Japanese Journal of Appl. Phys. Vol. 26, No. 6, (June 1987) L1032. 
[15]H. Yokoyama, M. Okamoto, T. Hamada, and Y. Osaka, "Growth Mechanism of Cubic Boron Nitride Prepared by Plasma CVD," Proc. 12th Symp. on ISIAT '89 (1989) 381.

[16]J. Hopwood, D. K. Reinhard, and J. Asmussen, "Experimental Conditions for Uniform Anisotropic Etching of Silicon with a Microwave Electron Cyclotron Resonance Plașma System," J. Vac. Sci. Technol. B 6 (6), (Nov/Dec 1988) 1896.

[17]T. Matsuura, H. Uetake, T. Ohmi, J. Murota, K. Fukuda, N. Mikoshiba, T. Kawashima, and Y. Yamashita, "Directional Etching of Si with Perfect selectivity to $\mathrm{SiO}_{2}$ Using an Ultraclean Electron Cyclotron Resonance Plasma," Appl. Phys. Lett 56 (14), (April 1990) 1339.

[18]T. Ono, M. Oda, C. Takahashi, and S. Matsuo, "Reactive Ion Stream Etching Utilizing Electron Cyclotron Resonance Plasma," J. Vac. Sci. Technol. B4 (3) (May/June 1986) 696.

[19]S. Samukawa, Y. Suzuki, and M. Sasaki, "Extremely High-Selective Electron Cyclotron Resonance Plasma Etching for Phosphorus-Doped Polycrystalline Silicon," Appl. Phys. Lett 57 (4), (July 1990) 403.

[20]K. Asakawa and S. Sugata, "Optical Emission Spectrum of $\mathrm{Cl}_{2}$ ECR Plasma in the GaAs Reactive Ion Beam Etching (RIBE) System," Japanese Journal of Appl. Phys. Vol. 23, No. 3, (March 1984) L156.

[21]C. Constantine, D. Johnson, S.J. Pearton, U.K. Chakrabarti, A.B. Emerson. W.S. Hobson, and A.P. Kinsella, "Plasma Etching of III-V Semiconductors in CH4/H2/Ar Electron Cyclotron Resonance Discharges," J. Vac. Sci. Technol. B 8 (4), (July/Aug. 1990) 596.

[22]B. Mizuno, I. Nakayama, N. Aoi, M. Kubota, T. Komeda, "New Doping Method for Subhalf Micron Trench Sidewalls by Using an Electron Cyclotron Resonance Plasma," Appl. Phys. Lett. 53 (21), (November 1988) 2059. 
[23]C. Hashimoto, K. Machida, and H. Oikawa, "New Taper-Etching Technology Using

Oxygen Ion Plasma," J. Vac. Sci. Technol. B 8(3), (May/June 1990) 529.

[24]F. F. Chen, "Introduction to Plasma Physics and Controlled Fusion," Vol 1: Plasma Physics, Plenum Press (1984).

[25]R. Limpaecher and K. R. MacKenzie, Rev. Sci. Instrum. 44, (1973) 726.

[26]R. R. Burke and C. Pomot, "Microwave Multipolar Plasma for Etching and Deposition," Vol. 31 (February 1988) 67.

[27]J. Asmussen, "Electron Cyclotron Resonance Microwave Discharges for Etching and Thin-Film Deposition," J. Vac. Sci. Technol. A7 (3), (May/June 1989) 883.

[28]S. M. Gorbatkin, L. A. Berry, and J. B. Roberto, "Behavior of Ar Plasmas Forrned in a Mirror Field Electron Cyclotron Resonance Microwave Ion Source," J. Vac. Sci. Technol. A8 (3), (May/June 1990) 2893.

[29]W. M. Holber and J. Forster, "Ion Energetics in Electron Cyclotron Resonance Discharges," J. Vac. Sci. Technol. A8 (5), (Sep/Oct 1990) 3720.

[30]M. Matsuoka and K. Ono, "Magnetic Filed Gradient Effects on Ion Energy for Electron Cyclotron Resonance Microwave Plasma Stream," J. Vac. Sci. Technol. A6 (1) (Jan/Feb 1988) 25.

[31]L. Pomathiod, R. Debrie, Y. Arnal, and J. Pelletier, "Microwave Excitation of Large Volumes of Plasma at Electron Cyclotron Resonance in Multipolar Confinement," Physics Letters, Vol. 106A, No. 7 (December 1984) 301.

[32]D. L. Flamm and V. M. Donnelly, "The Design of Plasma Etchants," Plasma Chemistry and Plasma Processing, Vol. 1, No. 4 (1981) 317.

\section{DISCLAIMER}

This report was prepared as an account of work sponsored by an agency of the United States Government. Neither the United States Government nor any agency thereof, nor any of their employees, makes any warranty, express or implied, or assumes any legal liability or responsibility for the accuracy, completeness, or usefulness of any information, apparatus, product, or process disclosed, or represents that its use would not infringe privately owned rights. Reference herein to any specific commercial product, process, or service by trade name, trademark, manufacturer, or otherwise does not necessarily constitute or imply its endorsement, recommendation, or favoring by the United States Government or any agency thereof. The views and opinions of authors expressed herein do not necessarily state or reflect those of the United States Government or any agency thereof. 
Figure Captions

Figure 1. Magnetic field lines and surfaces of constant magnetic field modulus for an ASTeX ECR plasma source with the upper coil current at $200 \mathrm{~A}$ and the lower coil current at $170 \mathrm{~A}$. 'The coil seperation is $0.305 \mathrm{~m}$. The magnetic field labels are in Tesla.'

Figure 2. Outline drawing for a simple ECR source coupled to a permanent magnet multipole "bucket".

Figure 3. Reflected light from the central region of a 6 " silicon wafer. The bias voltage for this run was $70 \mathrm{~V}$. The various regions are : (a) and (e) laser on with plasma off; (b) polysilicon etching; (c) $\mathrm{SiO}_{2}$ etching; (d) underlying $\mathrm{Si}$ substrate etching (polysilicon and $\mathrm{SiO}_{2}$ have been cleared).

Figure 4. Polysilicon and $\mathrm{SiO}_{2}$ etch rates as a function of applied bias.

Figure 5. Selectivity (polysilicon etch rate divided by $\mathrm{SiO}_{2}$ etch rate) as a function of applied bias. 
ORNL-RWG 90M-3035 FED

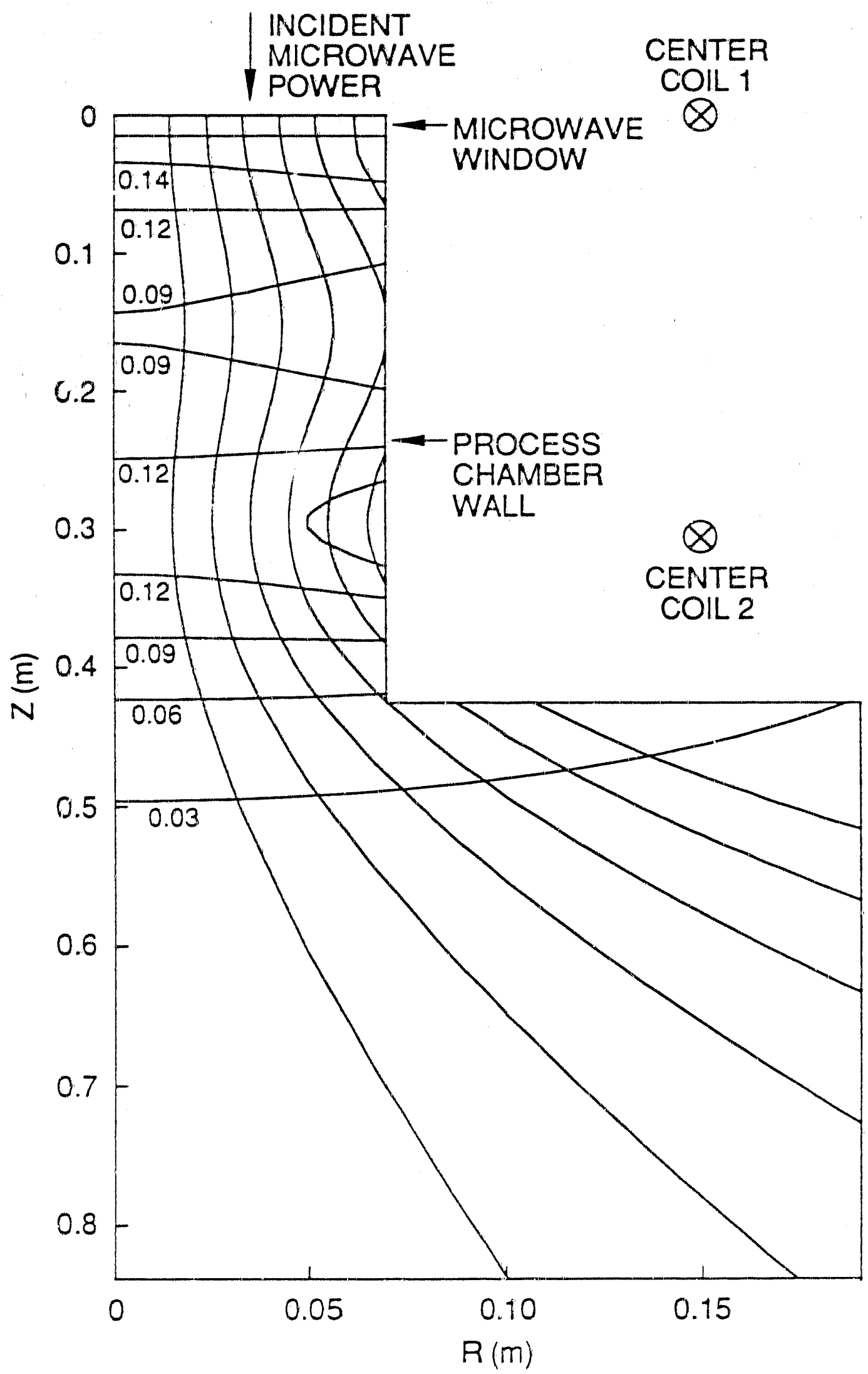




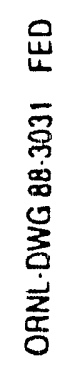

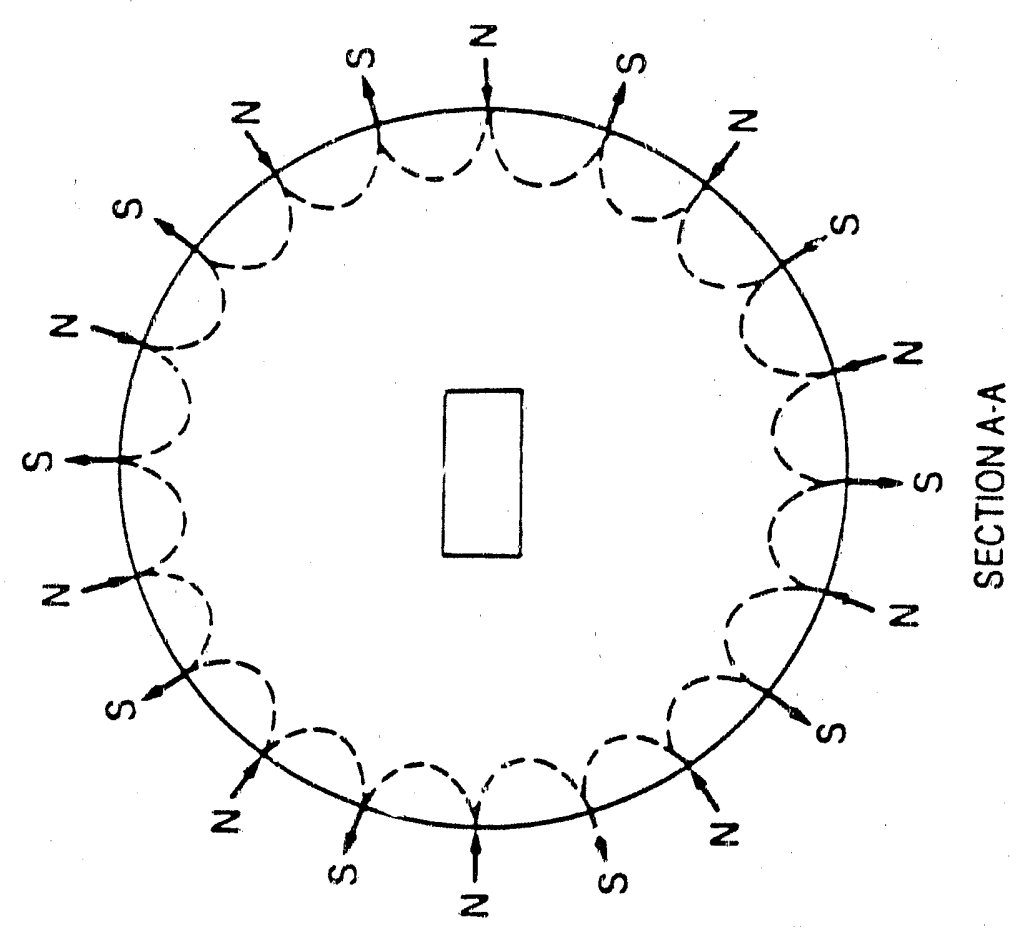

$\frac{2}{0}$

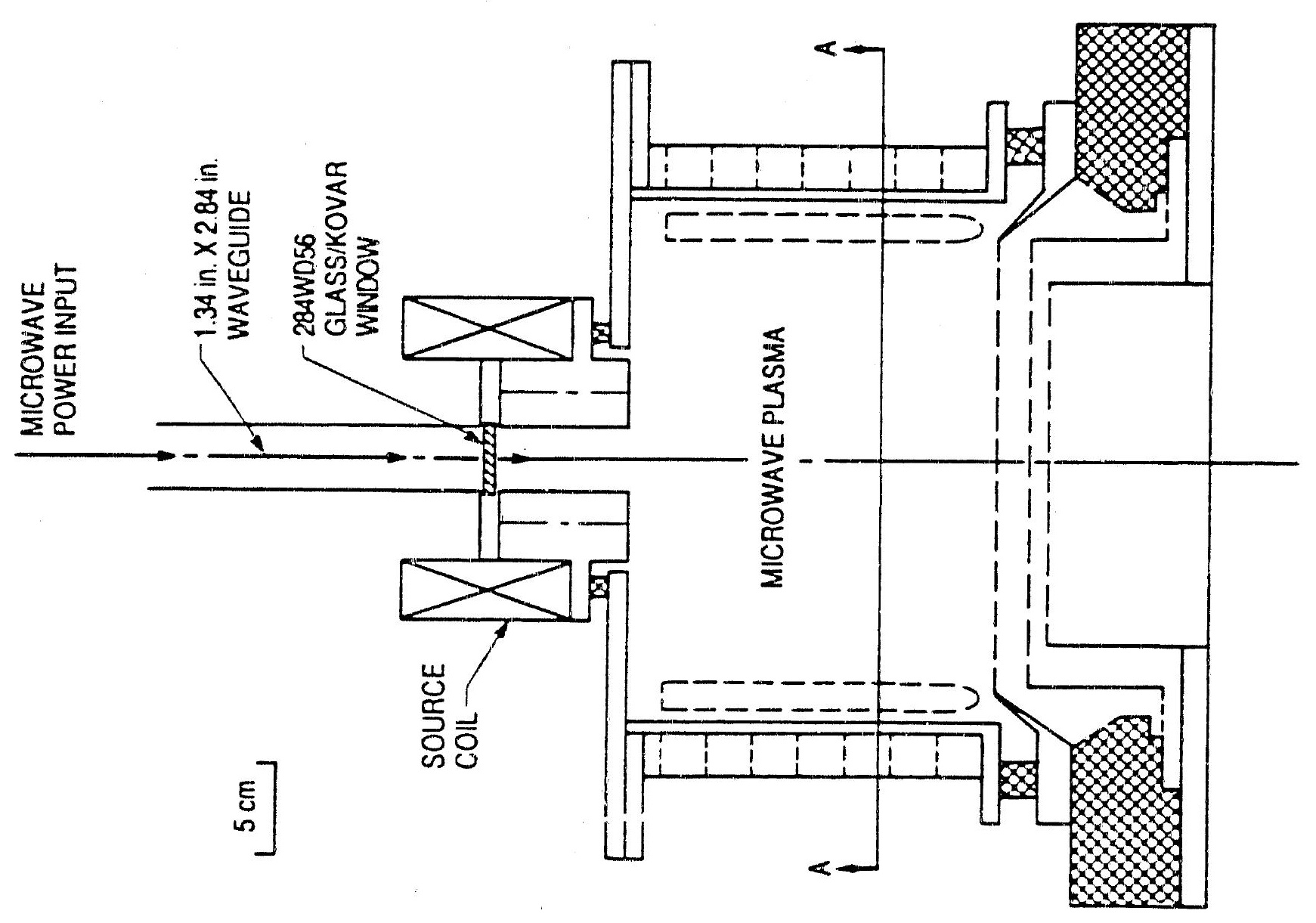


0
10
5
0
0
0
3
0
0
0
0
0

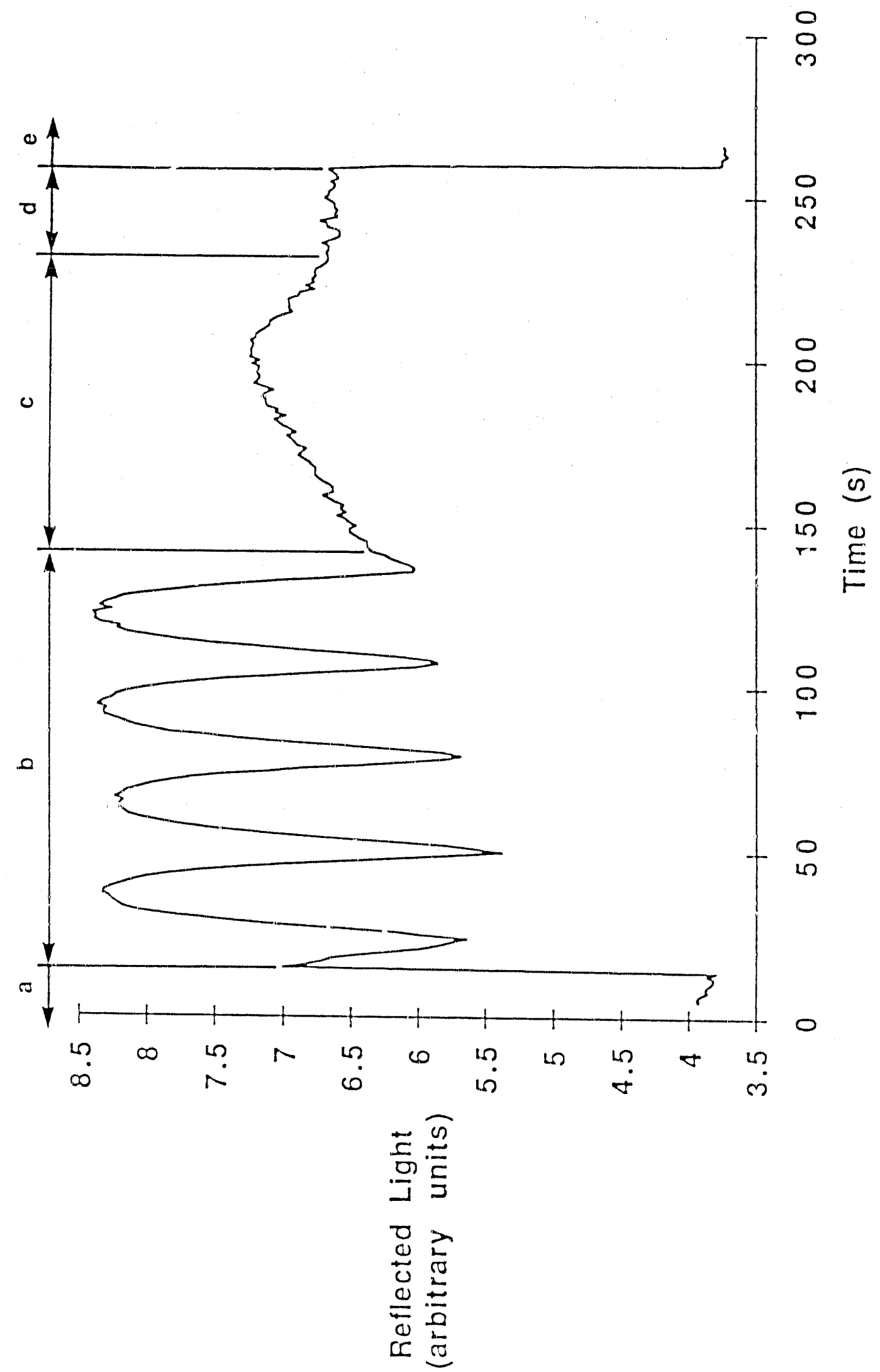

$r$ 

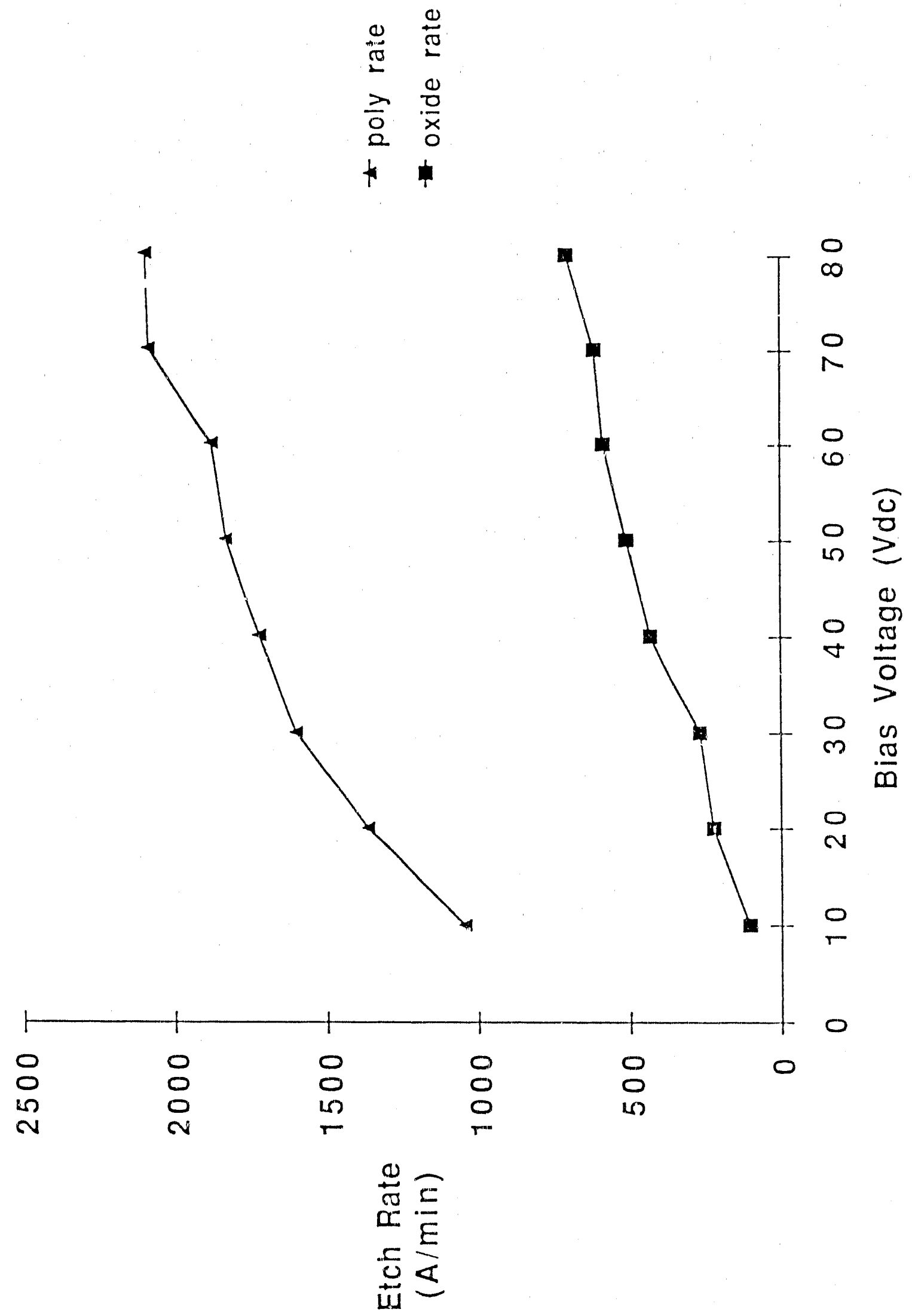
$\infty$
$\frac{1}{10}$
$\dot{0}$
0
0
3
0
$\dot{1}$
$\frac{1}{2}$
0

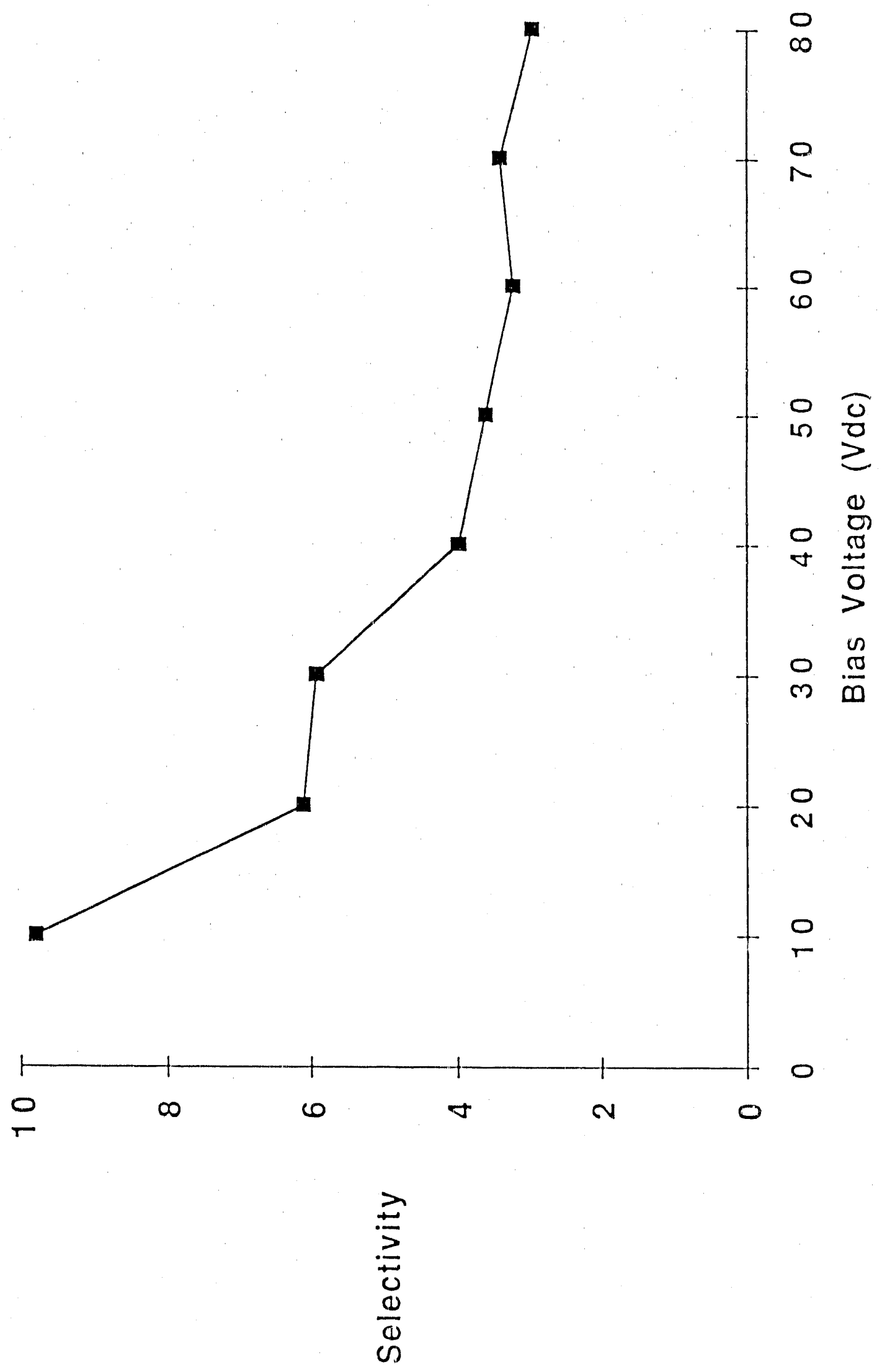



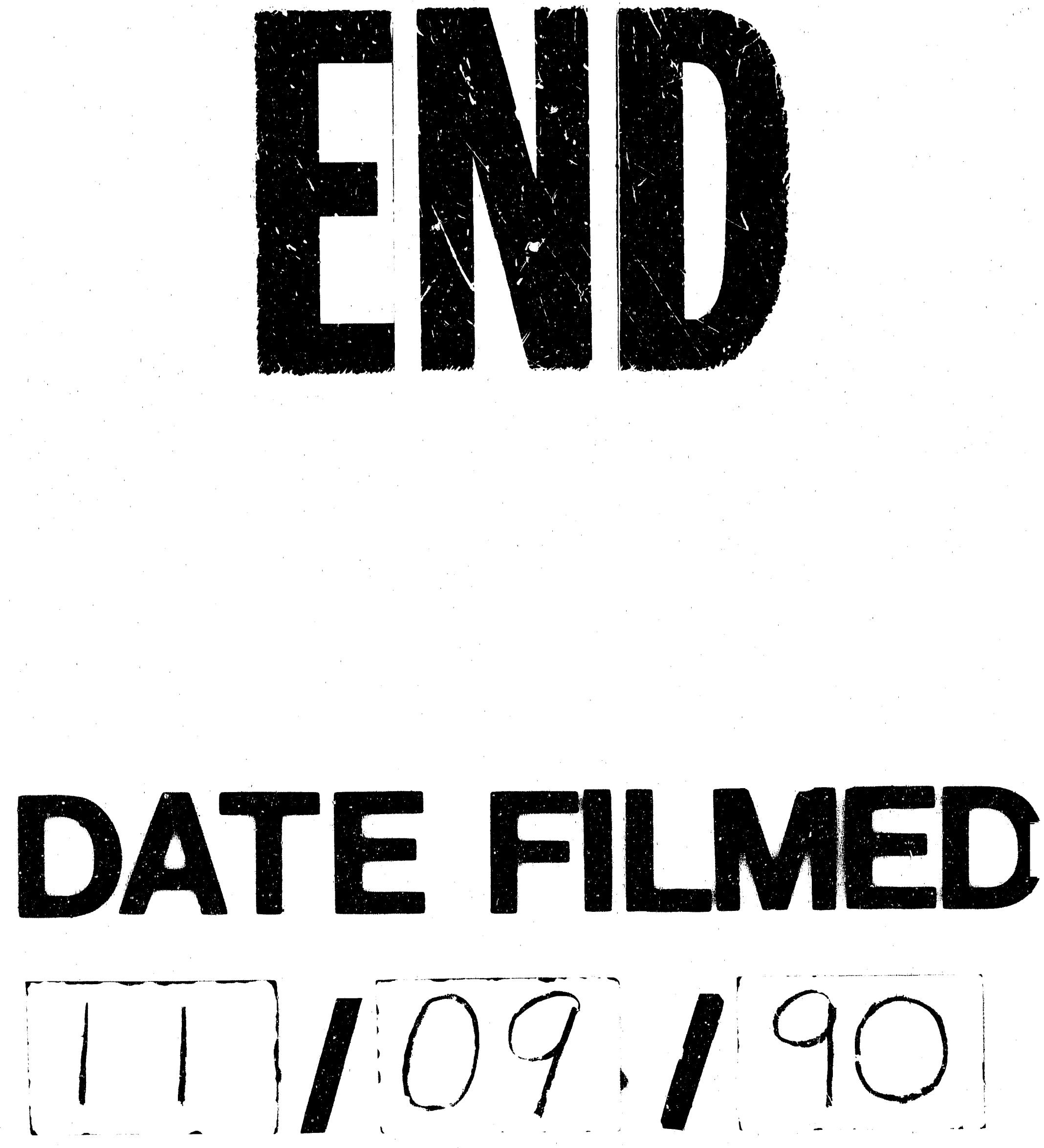
